\title{
A Survey on Swimming as a Fitness Practice Among Dental Students
}

\author{
Sabaritha. A ${ }^{1}$, Dhanraj Ganapathy² and L. Keerthi Sasanka ${ }^{3}$ \\ ${ }^{1}$ Saveetha dental college and hospitals, Saveetha institute of medical and technical science, \\ Saveetha university, 162, Poonamalle high road, Velapanchavadi, Chennai- 600077, India \\ ${ }^{2}$ Professor and Head, Department of Prosthodontics, Saveetha dental College, Saveetha Institute \\ of medical and technological science Saveetha University, Chennai, India 162, Poonamallee \\ High Road, Chennai - 600077, Tamil Nadu, India \\ ${ }^{3}$ Department of Prosthodontics, Senior Lecturer, Saveetha dental college and hospitals, \\ Saveetha institute of medical and technical science, Saveetha university, 162, \\ Poonamalle high road, Velapanchavadi, Chennai- 600077, India
}

\section{ABSTRACT}

Physical activity is basically required by an individual, which improves health and avoids illness . It plays an important role In rehabilitating the patients who have mental and physical illness . Health education, especially on physical fitness and nutrition. Academic pressure and comprehensive examination will lead to accumulated tension and anxiety.Swimming is an exercise that stretches the human body beyond its limits . It is an exercise that is done for soothing body ache and relaxes all the muscles . Swimming develops self concept and improves adaptive behaviour.Swimming motion showed excellent effect when compared to other sports in participants' health and reducing stress. This is a cross sectional survey was conducted among dental students through a self administrated questionnaire through an online survey link with google forms .The study population included dental students.The participants were explained about the purpose of study in detail.The questions were carefully studied and corresponding answers were marked by the participants. The responses were collected and the results were analysed.83.5\% of the dental students believed that fitness is really important for a dental graduate and only $16.5 \%$ of dental students did not agree to it . $71.6 \%$ of the dental students choose swimming as a good alternative for all the previously mentioned fitness regimes .So many studies showed that physical activities are very important for human health. Therefore, it can be said that the present study results supported many studies done about the physical activities and psychological health in the past and current literature. Swimming is also liked by a lot of people but due to insufficient time most of them do not practice it.

KEY WORDS: NUTRITION ; HEALTH ; PHYSICAL FITNESS ; SWIMMING.

\section{ARTICLE INFORMATION}

*Corresponding Author: dhanarajmganapathy@yahoo.co.in Received 28th July 2020 Accepted after revision 29th Sep 2020 Print ISSN: 0974-6455 Online ISSN: 2321-4007 CODEN: BBRCBA

Thomson Reuters ISI Web of Science Clarivate Analytics USA and Crossref Indexed Journal

\section{Clarivate
Analytics}

NAAS Journal Score 2020 (4.31) SJIF: 2020 (7.728)

A Society of Science and Nature Publication,

Bhopal India 2020. All rights reserved.

Online Contents Available at: http//www.bbrc.in/

Doi: http://dx.doi.org/10.21786/bbrc/13.8/161 


\section{INTRODUCTION}

Physical activity is basically required by an individual, which improves health and avoids illness(Irazusta et al., 2006; Kim and Park, 2006) (Tsai and Kao, 2010). It plays an important role In rehabilitating the patients who have mental and physical illness (Kim and Park, 2006). Current lifestyle is associated with an increase in pathology of all the physiological systems of the human body (Kassim, Othman and Ujang, 2020).lack of nutrition also plays an impotent role in the ethology of diseases (Kurosaka et al., 2018). Health education, especially on physical fitness and nutrition is necessary for health care workers (Mohammed, 2019) but, Modern lifestyle has reduced human activity due to automation which will lead to a sedentary lifestyle (Lee and Oh, 2015).

Stress is a matter of perception, the students in professional courses like medicine, dentistry, nursing or other paramedical courses have extensive working hours which creates stressful conditions in the students (Paykel, 1976; Jain and Jain, 2012).(Garbee, Zucker and Selby, 1980; Grover et al., 2018). This stress can be due to academic pressure and comprehensive examination will lead to accumulated tension and anxiety (Garbee, Zucker and Selby, 1980; Polychronopoulou and Divaris, 2005; Sudhakar, 2012). Continuous exposure of stress may lead to long-term work-related exhaustion and diminished interest (Jain and Jain, 2012; D et al., 2019). The consequences of stress may lead to mood alteration, tiredness, sleep disturbance, effect of performance, obsessive-compulsive disorders, severe level of depression, interpersonal sensitivity etc (Jain and Jain, 2012). These depression might be a greater burden among many students (Nabkasorn et al., 2006; Legrand, 2014). Stress and depression can be reduced by maintaining physiological fitness (Nabkasorn et al., 2006).

Swimming is an exercise that stretches the human body beyond its limits (Prentice, 2014; Foley, 2017). It is an exercise that is done for soothing body ache and relaxes all the muscles (Foley, 2017). Swimming develops self concept and improves adaptive behaviour (Kurokawa and Ikegami, 1980; Yilmaz et al., 2004). Mostly people prefer swimming as a hobby for pleasure (Huttunen, Kokko and Ylijukuri, 2004). There is a belief that swimming in cold water is beneficial to health (Huttunen, Kokko and Ylijukuri, 2004). Swimming reduces tiredness and fatigue, improves self esteem, boosts mood and relieves pain from many diseases (Huttunen, Kokko and Ylijukuri, 2004). Swimming motion showed excellent effect when compared to other sports in participants' health and reducing stress (Berger and Humphrey, 1986; Judge et al., 1993) (Huttunen, Kokko and Ylijukuri, 2004; Lee and Oh, 2013).

The purpose of this study is to determine that water exercises and swimming are motor exercises which will improve the physical fitness of the dental students (Yilmaz et al., 2004). One of the most important factors is to maintain the fitness of dental students and their attitude towards health promotion. (Kassim, Othman and Ujang, 2020). No previous study is based on the topic “ swimming as a fitness practice among dental students “. Though several physical fitness practices are available, swimming is an activity which involves movement of all parts of the body, all the muscles are stretched and relaxed during this exercise also it is very helpful to cope up with stress, to improve the physical fitness of our body and maintain a good healthy lifestyle.

Previously our department has published extensive research on various aspects of prosthetic dentistry ('Evaluation of Corrosive Behavior of Four Nickelchromium Alloys in Artificial Saliva by Cyclic Polarization Test:An in vitro Study', 2017;(Avula et al., 2017; Ganapathy, Kannan and Venugopalan, 2017; Jain, Ranganathan and Ganapathy, 2017)(Gupta, Ariga and Deogade, 2018; Mahmod et al., 2018; Ashok and Ganapathy, 2019; Das et al., 2019; Duraisamy et al., 2019; Varghese, Ramesh and Veeraiyan, 2019) this vast research experience has inspired us to research about a survey as a fitness practice among dental students.

\section{MATERIAL AND METHODS}

This study had been conducted in dental college which included 109 dental students. A survey was conducted and a questionnaire was prepared through an online survey "Google forms", including the demographic data (gender, age, fitness, Weight, height, Mentality, Physical activities on their daily basis). The link was shared among the students. The questionnaire was carefully analysed and answered. The results of the survey were collected and statistically analysed.Clearance from Ethical committee of Saveetha college of dentistry was obtained with Ethical Committee Registration. The type of research is original study. The method of studying is simple random sampling. The independent variable are dental students. The dependent variables are hobbies. The types of statistics are descriptive statistics.

Figure 1: The pie chart representing the responses based on $83.5 \%$ of the dental students believed that fitness is really important for a dental graduate and only $16.5 \%$ of dental students did not agree to it.

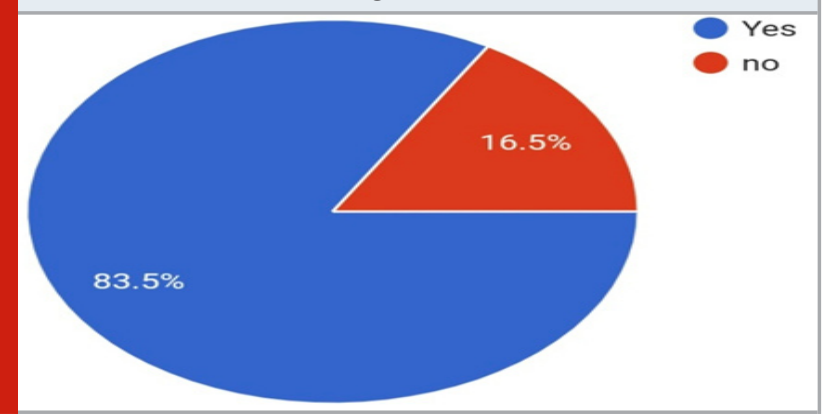

RESULTS

After collecting the results which were received after the circulation of survey through the online survey link the data was analysed. 83.5\% of the dental students 
believed that fitness is really important for a dental graduate and only $16.5 \%$ of dental students did not agree to it. (Figure 1). 20.2\% of the dental students felt that maintain an ace of physical fitness will improve overall ability , $46.8 \%$ of dental students think that maintaining physical fitness will reduce stress, 21.2\% think that physiological well being will be good and $11.9 \%$ think that physical fitness can be useful for maintaining all the above points (Figure 2). 57.8\% of the students say that fitness is improving good physique but $42.2 \%$ of the students say that the body should be maintained in an active and healthy position all the time (Figure 3). To maintain fitness 34.9\%of students preferred going to the gym, $32.1 \%$ of students preferred playing outdoor games, $20.2 \%$ of the students preferred doing yoga and $12.8 \%$ preferred doing all the above (Figure 4).

Figure 2: The pie chart representing the responses based on $20.2 \%$ of the dental students felt that maintain an ace of physical fitness will improve overall ability, $46.8 \%$ of dental students think that maintaining physical fitness will reduce stress, $21.2 \%$ think that physiological well being will be good and $11.9 \%$ think that physical fitness can be useful for maintaining all the above points.

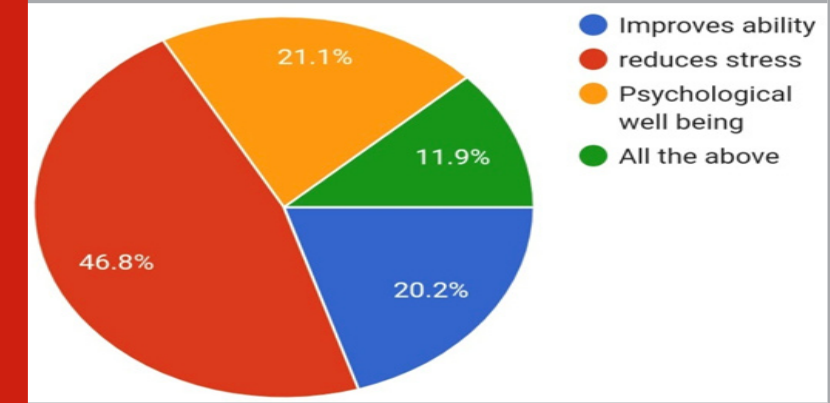

Figure 3: The pie chart representing the responses based on $57.8 \%$ of the students said that fitness is improving good physic but $42.2 \%$ of the students say that body should be maintained in an active and healthy position all the time.



In the common fitness regime employed by most of the students $26.6 \%$ of the preferred jogging, $48.6 \%$ preferred weight lifting, $13.8 \%$ traditional exercises and $11 \%$ swimming (Figure 5). $71.6 \%$ of the dental students choose swimming as a good alternative for all the previously ment fitness regimes and only $28.4 \%$ of the students have opposed it (Figure 6). $23.9 \%$ of the people felt that swimming is useful than other exercises because it maintains overall health, $51.4 \%$ of dental students say that occurs due to weight reduction, $16.5 \%$ of the dental students felt that it is due to increasing muscular energy and $8.3 \%$ of the students prefer all the above (Figure 7).84.4\% of the dental students know the fact that swimming everyday causes ill effects on health and $15.2 \%$ of dental students have no idea about it (Figure 8). $71.6 \%$ of the dental students are aware that swimming in the same pool might lead to skin ,eye,ear infection and $28.4 \%$ are not aware of that (Figure 9). $78 \%$ of the students know that swimming is an exercise that would reduce our stress level and 22\% of the dental students are not aware that swimming gives relief from stress (Figure 10).

Figure 4: The pie chart representing the responses based on maintaining fitness $34.9 \%$ of students preferred going to gym,32.1\% of students preferred playing outdoor games, $20.2 \%$ of the students preferred doing yoga and $12.8 \%$ preferred doing all the above.

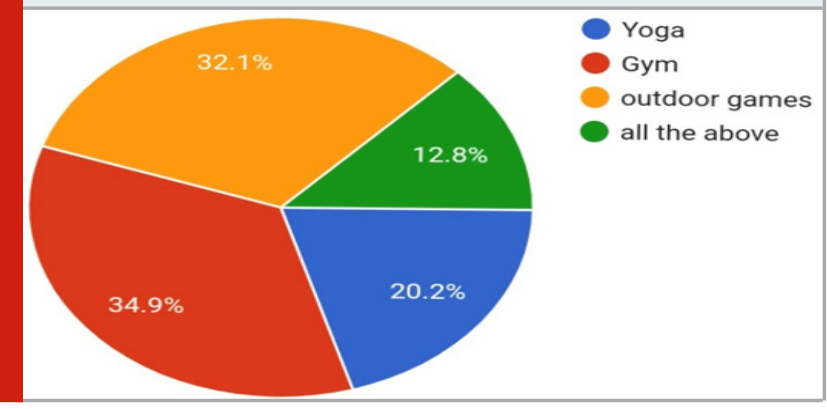

Figure 5: The pie chart representing the responses based on common fitness regime employed by most of the students $26.6 \%$ of the preferred jogging, $48.6 \%$ preferred weight lifting, $13.8 \%$ traditional exercises and $11 \%$ swimming.

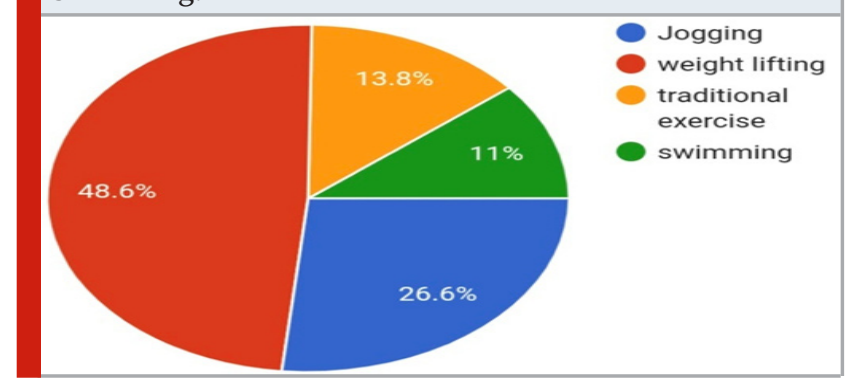

\section{DISCUSSION}

This study makes it very evident that swimming is one of the fitness practices followed by dental students. BDS is a professional course where the students are taking a lot of stress and so much of workload. Most of them do not tend to maintain a proper balanced diet. Some people take in too much stress that they don't even have time to do physical exercise and keep their body healthy. Swimming is an exercise where your whole body gets to move. One hour of swimming daily will improve your physical fitness and health conditions. Majority of the students (83.4\%) knew that physical fitness was really 
important in the students who are in the field of BDS. There was a similar study done(Hou et al., 2020) where $74 \%$ of the people were aware that physical fitness was really important to improve human health.

Figure 6: The pie chart representing the responses based on $71.6 \%$ of the dental students choose swimming as a good alternative for all the previously mentioned fitness regimes and only $28.4 \%$ of the students have opposed it.

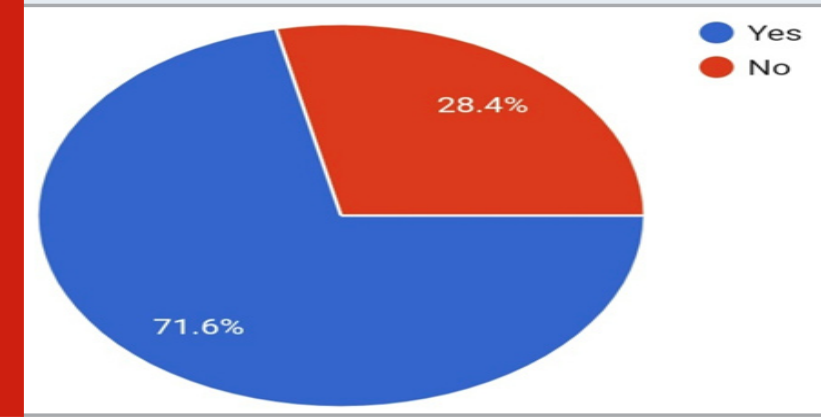

Figure 7: The pie chart representing the responses based on $23.9 \%$ of the people felt that swimming is useful than other exercises because it maintains overall health, 51.4 $\%$ of dental students say that weight reduction, $16.5 \%$ of the dental students increasing muscular energy and 8.3 $\%$ prefer all the above.

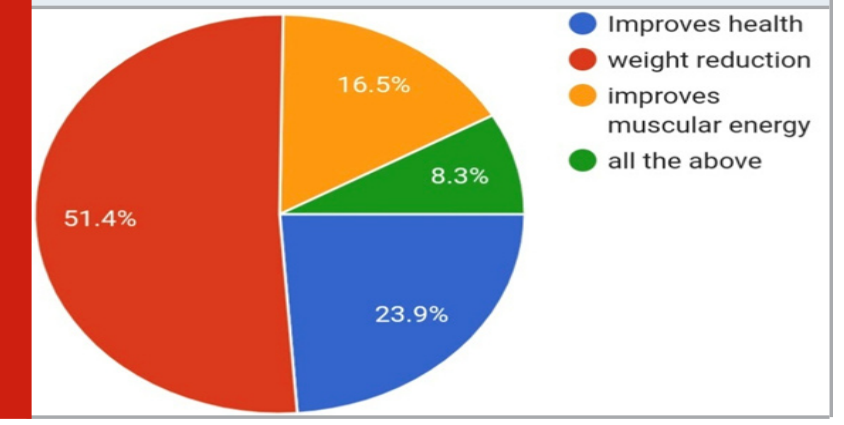

Figure 8: The pie chart representing the responses based on $84.4 \%$ of the dental students know the fact that swimming everyday causes ill effects on health and 15.2\% of dental students have no idea about it.

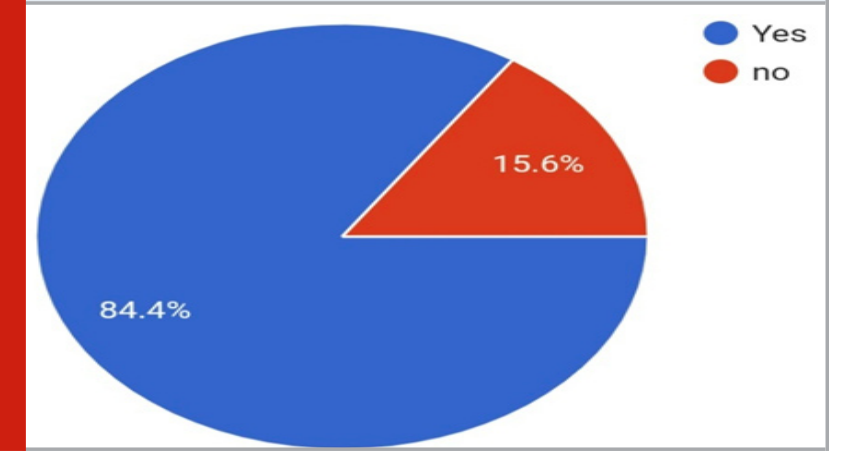

There are no opposing articles regarding it(Hou et al., 2020).Majority of the participants (78\%) felt that swimming is a sport that causes stress relief among dental students. There is an article which has a similar finding (David et al., 2019) where 82\% of the population felt that doing physical activity would relieve stress in people. There are no opposing articles(David et al., 2019) . Majority of the students $48.2 \%$ were aware that physical fitness will reduce health. There was a similar finding in (United States. Office of Education. Committee on Wartime Physical Fitness for Colleges and Universities, 1943) where $50 \%$ of the participants felt that physical fitness is important to reduce stress.

Figure 9: The pie chart representing the responses based on $71.6 \%$ of the dental students are aware that swimming in the same pool might lead to skin,eye,ear infection and $28.4 \%$ are not aware of that.

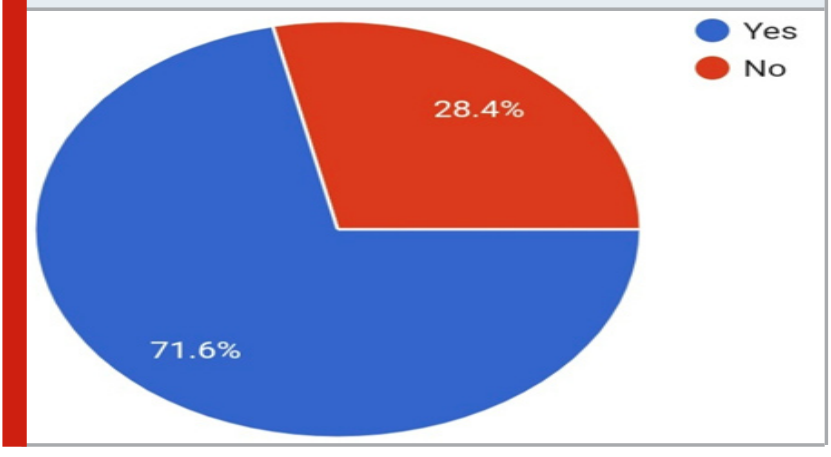

Figure 10: The pie chart representing the responses based on 78\% of the students know that swimming is an exercise that would reduce our stress level and $22 \%$ of the dental students are not aware that swimming gives relief from stress.

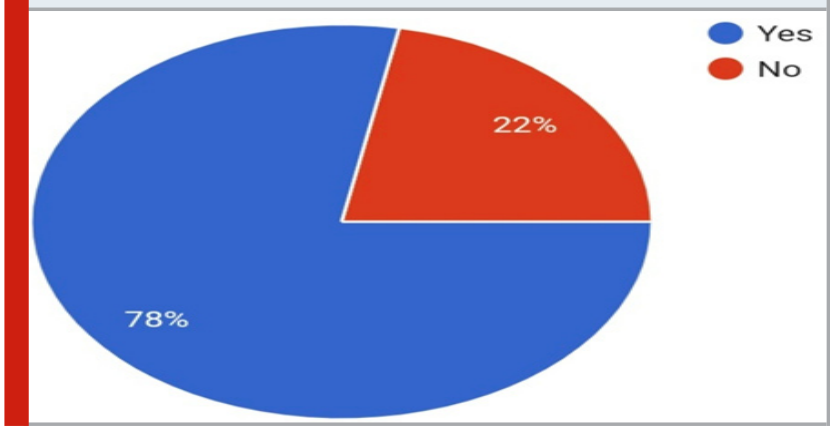

There are no opposing articles. Majority of the students ( 48.6\%) preferred jogging as an easy way to keep up physical fitness. There was a similar finding in ((Kornev, 2018) where 55\% of the people also preferred jogging as an easier method to improve physical fitness. There are no opposing articles. According to Rosenstock (1990), the more susceptibility or seriousness is perceived, the more health belief model is active in practice of health behavior, the other way, practice of health behavior has been decreased, when a barrier to this kind of behavior is perceived (Lee and Oh, 2013; Lee and Lee, 2014). This theory states that patients in swimming have a higher susceptibility and concern for health (Lee and Oh, 2013). Study by Son et al. (2009) also reported that lack of exercise will lead to serious diseases ((Lee and Oh, 2013). (Berger \&t:Owen, 198 , 1986, in press) stress reduction due to swimming is surprising (Berger and Owen, 1988). 
Positive mood benefits are found in swimmers (Berger and Owen, 1988). There haven't been so many studies done under the topic swimming as a fitness practice among dental students.This is a new study, where no research has been done on this particular topic.If further studies are done it would be very effective to find out new ways to reduce stress and improve physical fitness.

\section{CONCLUSION}

So many studies showed that physical activities are very important for human health. Therefore, it can be said that the present study results supported many studies done about the physical activities and psychological health in the past and current literature. Swimming is also liked by a lot of people but due to insufficient time most of them do not practice it.

\section{REFERENCES}

Ashok, V. and Ganapathy, D. (2019) 'A geometrical method to classify face forms', Journal of oral biology and craniofacial research, 9(3), pp. 232-235.

Avula, K. et al. (2017) 'A RETROSPECTIVE STUDY OF ROLE OF HYSTEROLAPAROSCOPY IN THE EVALUATION OF FEMALE INFERTILITY, IN 100 PATIENTS IN A PRIVATE HOSPITAL OVER A PERIOD OF TWO YEARS', Journal of Evolution of Medical and Dental Sciences, pp. 3955-3958. doi: 10.14260/jemds/2017/856.

Berger, B. G. and Owen, D. R. (1988) 'Stress Reduction and Mood Enhancement in Four Exercise Modes: Swimming, Body Conditioning, Hatha Yoga, and Fencing', Research Quarterly for Exercise and Sport, pp. 148-159. doi: 10.1080/02701367.1988.10605493. Das, A. et al. (2019) 'Highly Active Urea-Functionalized Zr(IV)-UiO-67 Metal-Organic Framework as Hydrogen Bonding Heterogeneous Catalyst for Friedel-Crafts Alkylation', Inorganic chemistry, 58(8), pp. 51635172.

David et al. (2019) 'Physical Fitness among the Dental Physician, Dental Undergraduates and Postgraduates Students', Indian Journal of Public Health Research \&t Development, p. 223. doi: 10.5958/09765506.2019.02801.8.

D, D. B. et al. (2019) 'A comparative study of stress among students of Dental and Engineering Colleges of Annamalai University', Journal of Medical Science And clinical Research. doi: 10.18535/jmscr/v7i10.114.

Duraisamy, A. J. et al. (2019) 'Epigenetic Modifications in Peripheral Blood as Potential Noninvasive Biomarker of Diabetic Retinopathy', Translational vision science Et technology, 8(6), p. 43.

Foley, R. (2017) 'Swimming as an accretive practice in healthy blue space', Emotion, Space and Society, pp. 43-51. doi: 10.1016/j.emospa.2016.12.001.

Ganapathy, D. M., Kannan, A. and Venugopalan, S.
(2017) 'Effect of Coated Surfaces influencing Screw Loosening in Implants: A Systematic Review and Metaanalysis', World Journal of Dentistry, pp. 496-502. doi: 10.5005/jp-journals-10015-1493.

Garbee, W. H., Zucker, S. B. and Selby, G. R. (1980) 'Perceived Sources of Stress Among Dental Students', The Journal of the American Dental Association, pp. 853-857. doi: 10.14219/jada.archive.1980.0279.

Grover, S. et al. (2018) 'Perceived Sources of Stress among Undergraduate Dental Students in a Dental College in North India', Indian Journal of Youth and Adolescent Health, pp. 7-14. doi: 10.24321/2349.2880.201807. Gupta, P., Ariga, P. and Deogade, S. C. (2018) 'Effect of Monopoly-coating Agent on the Surface Roughness of a Tissue Conditioner Subjected to Cleansing and Disinfection: A Contact Profilometric Study', Contemporary clinical dentistry, 9(Suppl 1), pp. S122S126.

Hou, Y. et al. (2020) 'Physical Fitness with Regular Lifestyle Is Positively Related to Academic Performance among Chinese Medical and Dental Students', BioMed research international, 2020, p. 5602395.

Huttunen, P., Kokko, L. and Ylijukuri, V. (2004) 'Winter swimming improves general well-being', International journal of circumpolar health, 63(2), pp. 140-144.

Irazusta, A. et al. (2006) 'Exercise, Physical Fitness, and Dietary Habits of First-Year Female Nursing Students', Biological Research For Nursing, pp. 175-186. doi: 10.1177/1099800405282728.

Jain, A., Ranganathan, H. and Ganapathy, D. (2017) 'Cervical and incisal marginal discrepancy in ceramic laminate veneering materials: A SEM analysis', Contemporary Clinical Dentistry, p. 272. doi: 10.4103/ ccd.ccd_156_17.

Jain, D. A. and Jain, A. (2012) 'Stress among Medical and Dental Students: A Global Issue', IOSR Journal of Dental and Medical Sciences, pp. 5-7. doi: 10.9790/08530150507.

Kassim, M., Othman, N. and Ujang, E. (2020) 'The Level of Physical Fitness among First Year Female Students in National Defence University of Malaysia', Journal of Physics: Conference Series, p. 022072. doi: 10.1088/1742-6596/1529/2/022072.

Kim, H. D. and Park, J. S. (2006) 'The Effect of an Exercise Program on Body Composition and Physical Fitness in Obese Female College Students', Journal of Korean Academy of Nursing, p. 5. doi: 10.4040/ jkan.2006.36.1.5.

Kornev, A. (2018) 'Formation Of Students' Personal Physical Culture In Preparation For Physical Fitness Tests'. doi: 10.15405/epsbs.2018.02.73.

Kurokawa, T. and Ikegami, H. (1980) 'EFFECTS OF BODY POSITIONS, WATER IMMERSION, AND SWIMMING 
TRAINING ON HUMAN LUNG MECHANICS', Japanese Journal of Physical Fitness and Sports Medicine, pp. 98-109. doi: 10.7600/jspfsm 1949.29.98.

Kurosaka, Y. et al. (2018) 'Protective effects of dietary restriction and physical exercise on intrahepatic fat accumulation', The Journal of Physical Fitness and Sports Medicine, pp. 9-14. doi: 10.7600/jpfsm.7.9.

Lee, B.-A. and Oh, D.-J. (2013) 'The effects of health perception on living health belief, living satisfaction and wellbeing-oriented activities according to swimming participation with middle-aged women', Journal of Exercise Rehabilitation, pp. 381-388. doi: 10.12965/ jer. 130047.

Lee, B.-A. and Oh, D.-J. (2015) 'Effect of regular swimming exercise on the physical composition, strength, and blood lipid of middle-aged women', Journal of Exercise Rehabilitation, pp. 266-271. doi: 10.12965/jer.150242.

Lee, B. and Lee, J. (2014) 'Effects of Social Activity Participation and Degree the Flow on the Psychological Well-being of Korean Middle-Aged Women', The Korean Journal of Community Living Science, pp. 349-361. doi: 10.7856/kjcls.2014.25.3.349.

Legrand, F. D. (2014) 'Effects of Exercise on Physical Self-Concept, Global Self-Esteem, and Depression in Women of Low Socioeconomic Status With Elevated Depressive Symptoms', Journal of Sport and Exercise Psychology, pp. 357-365. doi: 10.1123/jsep.20130253.

Mahmod, M. et al. (2018) 'The interplay between metabolic alterations, diastolic strain rate and exercise capacity in mild heart failure with preserved ejection fraction: a cardiovascular magnetic resonance study', Journal of cardiovascular magnetic resonance: official journal of the Society for Cardiovascular Magnetic Resonance, 20(1), p. 88.

Mohammed, A. (2019) 'Effects of Regular Exercise Programme on the Health Related Physical Fitness of Obese and Non-Obese Female Undergraduate Students', International Journal of Scientific and
Research Publications (IJSRP), p. 8972. doi: 10.29322/ ijsrp.9.05.2019.p8972.

Nabkasorn, C. et al. (2006) 'Effects of physical exercise on depression, neuroendocrine stress hormones and physiological fitness in adolescent females with depressive symptoms', European Journal of Public Health, pp. 179-184. doi: 10.1093/eurpub/cki159.

Paykel, E. S. (1976) 'Life Stress, Depression and Attempted Suicide', Journal of Human Stress, pp. 3-12. doi: 10.1080/0097840x.1976.9936065.

Polychronopoulou, A. and Divaris, K. (2005) 'Perceived Sources of Stress Among Greek Dental Students', Journal of Dental Education, pp. 687-692. doi: 10.1002/j.00220337.2005.69.6.tb03952.x.

Prentice, R. (2014) 'Swimming in the Joint', Representation in Scientific Practice Revisited, pp. 89-106. doi: 10.7551/mitpress/9780262525381.003.00 05.

Sudhakar, K. (2012) 'PERCEIVED SOURCES OF STRESS AMONG DENTAL STUDENTS IN SOUTH INDIA', annals and essences of dentistry, pp. 43-51. doi: 10.5368/ aedj.2012.4.1.1.8.

Tsai, C.-C. and Kao, Y.-L. (2010) 'Changes of Physical Activity Level and Physical Fitness in Adolescent Students within One Year', Medicine \& Science in Sports \& Exercise, p. 525. doi: 10.1249/01. mss.0000385287.41077.f4.

United States. Office of Education. Committee on Wartime Physical Fitness for Colleges and Universities (1943) Handbook on Physical Fitness for Students in Colleges and Universities.

Varghese, S. S., Ramesh, A. and Veeraiyan, D. N. (2019) 'Blended Module-Based Teaching in Biostatistics and Research Methodology: A Retrospective Study with Postgraduate Dental Students', Journal of dental education, 83(4), pp. 445-450.

Yilmaz, I. et al. (2004) 'Effects of swimming training on physical fitness and water orientation in autism', Pediatrics international: official journal of the Japan Pediatric Society, 46(5), pp. 624-626. 